\title{
Perception Comparisons on Packaging Design Elements toward Purchasing Decisions between People with Art Sensibility and Those without Art Sensibility
}

\author{
Khwanrat Chinda \\ Pohchang Academy of Arts, Rajamangala University Of Technology Rattanakosin \\ khwanrat.ch@rmutr.ac.th
}

\begin{abstract}
Perception on product appearance could enhance customers' credentials for product quality and increase the purchasing potential. In this study a testing by using a set of 3D simulated pictures as stimuli is designed to evaluate how consumers perceived product necessity of cognitive and affective perceptions that lead to the purchasing decision by means of structured questionnaire between a person with Art Sensibility and people without art sensibility. The results found that people with Art Sensibility and people without Art sensibility perceived differently for the following attributes: type of product, price of product, quality of product and purchasing decision. From multiple regression analyses, the authors found that the predictors correlated highly with consumers' intentions to purchase the product. All attributes about perception had positive significant regression. Finally, the result will be used to create an initial set of design guideline for packaging that attract consumer to purchase the product.
\end{abstract}

Keywords: Elements of design, perception, packaging appearance, purchasing decision, Sensibility of Art

\section{INTRODUCTION AND LITERATURE REVIEW}

The research focuses on consumer perceiving testing which is relates and bases on three lines of thoughts, namely, theories marketing strategies, elements and principle of visual design, and product perception method test.

Marketing strategy based on understanding of consumer behavior such as needs, attitudes, predispositions in order to design successful marketing mixs that using control variables, for example, packaging, pricing, and advertising (Leon G.Schiffman and Leslie Lazar Kanuk, 2000. While as marketing strategy attempts to convey consumer to purchase the product, packaging could be a means to reflect the quality and characteristics of products by using graphical features (Pires Gon ${ }_{s}$ calves, Ricardo,2008(.

Elements of design or visual elements is the first important basis for all of design. Particular in this study packaging image is among the important approaches to convey the product value and trust to persuade the purchasers' decision by using elements of design. Shape and color have meanings and communicated to consumer perceived product quality (Pires Gon ${ }_{3}$ calves, Ricardo,2008. Furthermore, packaging Structure and graphic are important to consider in the design in order to

elements of packaging design have on Sensibility of Art person and non sensibility of art person consumers' decisions to purchase the product. This study focus communicate and tells the consumer about the product by using elements of design such as color, copy, picture (Herbert M.Meyers,1998) Consumer perceive the product position which relate each positioning strategy to certain specific packaging elements are colour, typography, shape, image )Olga Ampuero and Natalia Vila,2006(. This study focuses on visual and physical attribute of package design which is indicate and use to be variables to test consumer's perception are color, texture, picture, logo, typography, shape, and form (Wallschlaeger and BusicSnyder,1992) Product perception method test in this research aim to test relating of elements of design and visual perception factors in term of Composite measure; cognitive and affective leading to the consumer's purchasing intention (Hayden, 2009).

The previous study has shown that individual differences in perceived of art people were significantly different aspects of the same paintings and different respond in a work of art. (David O'Hare, 1976) There are many researchers that study the impacts of packaging on product quality, brand, and positioning. However, there is no research on the effects that sensibility of art may have on packaging. Thus, one of the objectives of this paper is to fill that gap, by studying the impact of sensibility of art on the packaging design. By attempting to answer two research questions, shown below, the paper will examine the effects that certai

summarize the relating between all theoretical and a conceptual model for this study is shown in Figure 1 below 


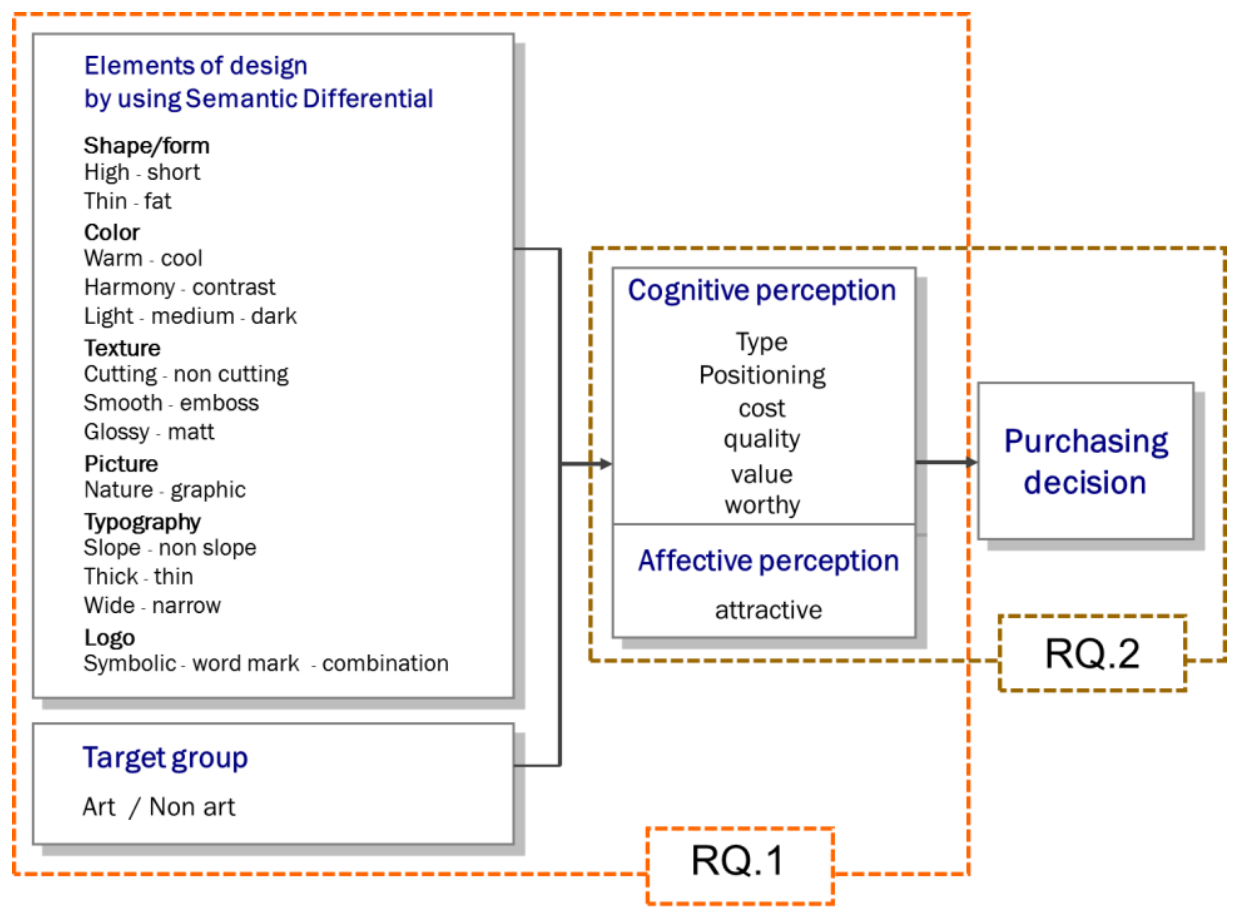

Figure 1. Conceptual and Research framework

Source: Khwanrat Chinda, 2016

\section{RESEARCH QUESTIONS}

Research Questions 1 Is there a significant difference in the mean perception score for Art sensibility and Non art sensibility person?

Research Questions 2 How well do the perception factors predict purchasing decisions?

\section{METHODOLOGY}

Stimuli are empirical research instrument effected to perception measurement were used in this study. Simulations are many ways to imitate natural conditions by mean in this research is visual perception conditions. Using re-creating an environment or other features by scale-model or other media is possible ) Barbara\&Robert sommer,1997( . Pires Gon,calves, Ricardo) 2008( used 2 dimension picture of shape and color in questionnaire and using a seven point semantic differential Likert scale to indicated perception. The other, Arthur Stamps reference in Architectural research methods ) Linda Grote and David Wang,2002( measures people's perception of architectural mass: from vague impressions to definite design features, uses picture stimuli from computer-generated façade stimuli as research tool.

The present study, data were collected within the framework and based on a simple random sampling of 137 consumers to determining the key graphic variables that indicated perception factors. For the variables in this study are the elements of package design has been created as a 3D stimuli was created in the form of pair images with 2 pictures; left and right that control all factors of 2 images except the only one testing factor totally 17 pairs ) 17 factors( that present in the first box of a Conceptual and Research framework that relating elements of design, perception, and purchase in Figure 1 A set of 3D visual graphical stimuli have been created in accordance with to test their effects against the perception on cognitive and affective leading to perception of the product by means of semantic differential self-report questionnaire and the 3D stimuli are based on fives scales of measurement. Level 5 is the highest on both sides. The sample groups are allowed to choose only one picture and one level score. If they determine that the two images are equally attractive for any question, they will select a score of 0 (Figure 2). 


\begin{tabular}{|l|l|l|l|l|l|l|l|l|l|l|l|l|}
\hline \multicolumn{2}{|c|}{ Perception factors } & \multicolumn{2}{|c|}{ Left } & \multicolumn{1}{c|}{$\begin{array}{l}\text { Not related } \\
\text { with factor }\end{array}$} \\
\hline
\end{tabular}

Figure 2. The example of semantic differential self-report questionnaire And the 3D stimuli (smooth texture / emboss texture) Source: Khwanrat Chinda, 2016

Lastly, the score will be transformed from left (5-1) to right (1-5) to the scale of 11-1, sorted from left to right to calculate the statistics shown in Table 1 . After

Table 1. Perception Level and Transformation Score

\begin{tabular}{|c|c|c|c|c|c|c|c|c|c|c|c|}
\hline & \multicolumn{5}{|c|}{ Left Stimulus } & & \multicolumn{5}{|c|}{ Right Stimulus } \\
\hline Perception Level & 5 & 4 & 3 & 2 & 1 & 0 & 1 & 2 & 3 & 4 & 5 \\
\hline Transformation Score & 11 & 10 & 9 & 8 & 7 & 6 & 5 & 4 & 3 & 2 & 1 \\
\hline
\end{tabular}

\section{RESULTS OF ANALYSIS}

The results are divided into 2 parts based on our research questions (see Figure 1). As a reminder, the first research question is: Is there a significant difference in the mean perception score for Art sensibility and Non art sensibility person? The second research question is: How well do the perception factors predict purchasing decisions? collecting the data, researchers analyzed the statistics to answer the research question.
Part One: The research conducted an independent-samples $\mathrm{T}$-test to compare the mean perception scores between Art sensibility and Non art sensibility person. The example of test found that there is a significant difference in the scores for perceived all perception factors related to stimuli glossy and matt texture except the perception of positioning for different person in art sensibility (Figure 3): 


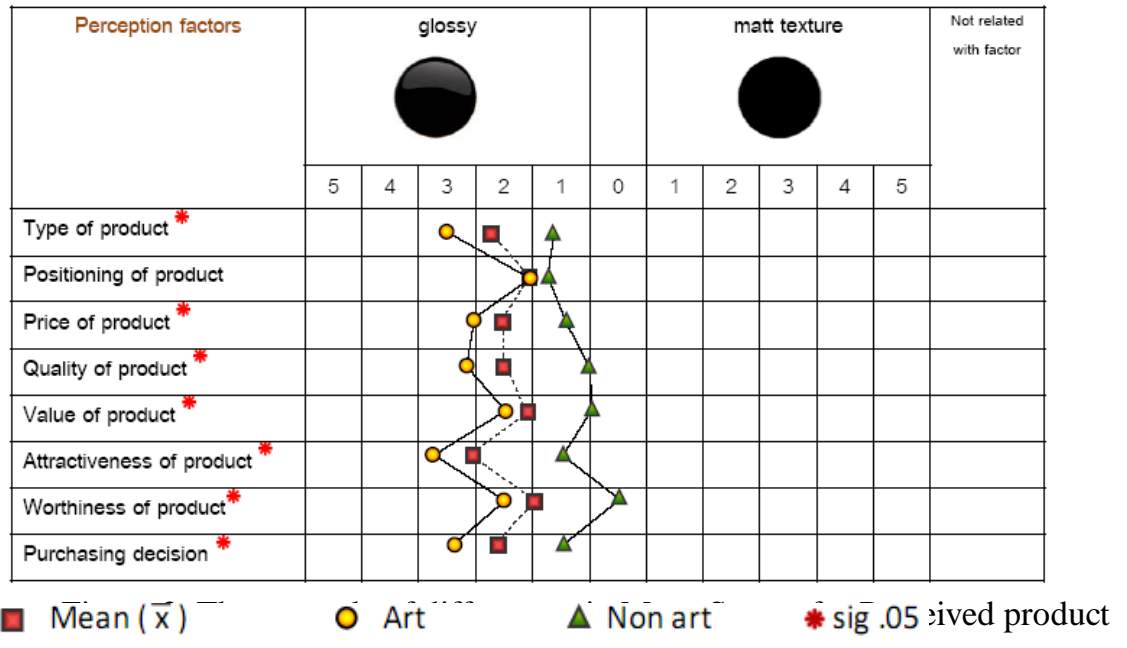

related to stimuli glossy and matt texture

Source: Khwanrat Chinda, 2016

The next example of result that has a significant difference in the scores for perceived some perception factors related to smooth texture and emboss texture is type, attractive, worthiness and purchasing decision for different person in art sensibility (Figure 4):

\begin{tabular}{|c|c|c|c|c|c|c|c|c|c|c|c|c|}
\hline \multirow[t]{2}{*}{ Perception factors } & \multicolumn{5}{|c|}{ smooth texture } & & \multicolumn{5}{|c|}{ emboss texture } & \multirow{2}{*}{$\begin{array}{l}\text { Not related } \\
\text { with factor }\end{array}$} \\
\hline & 5 & 4 & 3 & 2 & 1 & 0 & 1 & 2 & 3 & 4 & 5 & \\
\hline Type of product ${ }^{*}$ & & & & & & & $A$ & 0 & & & & \\
\hline Positioning of product & & & & & & & & & & & & \\
\hline Price of product & & & & & & & & के & & & & \\
\hline Quality of product & & & & & & & & 8 & & & & \\
\hline Value of product & & & & & & & & & & & & \\
\hline Attractiveness of product & & & & & & & 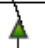 & 草 & 9 & & & \\
\hline Worthiness of product ${ }^{*}$ & & & & & & & $\Delta$ & 宜C & & & & \\
\hline Purchasing decision ${ }^{*}$ & & & & & & & $\Delta$ & 亩 & o & & & \\
\hline
\end{tabular}

Figure 4 The example of differences in Mean Scores for Perceived product related to smooth texture and emboss texture

Source: Khwanrat Chinda, 2016

Part Two: The researchers conducted multiple regression analyses to examine the relationship between consumers who intend to purchase luxury perfume and various luxury perception predictors of the nine stimuli pairs. The result presents only the regression details for the 2 pairs of stimuli that show the result in part one (glossy-matt texture, and smooth-emboss texture).

For Stimulus 1 the perception mean score for the glossy-matt texture suggests that the targets perceive the glossy texture as the most for all perception and purchasing, and the multiple regression model with all seven predictors produced $\mathrm{R}^{2}=.920$ at sig. $=.000$. As Table 1 shows, the perceptions for price of product, value of product, and attractiveness of product have significant positive regression weight, indicating that consumers with higher perception scores will likely purchase the product, after controlling for the other variables in the model. Perceptions of type, positioning, quality, and Worthiness of product did not contribute to the multiple regression model. 
Table 2. Results from the Regression Analysis of Stimulus 1: glossy-matt texture

\begin{tabular}{|c|c|c|c|c|c|c|}
\hline \multicolumn{2}{|c|}{ Model } & \multicolumn{2}{|c|}{$\begin{array}{l}\text { Unstandardized } \\
\text { Coefficients }\end{array}$} & \multirow{2}{*}{$\begin{array}{c}\begin{array}{c}\text { Standardized } \\
\text { Coefficients }\end{array} \\
\text { Beta }\end{array}$} & \multirow{3}{*}{$\begin{array}{l}\mathbf{t} \\
.024\end{array}$} & \multirow{3}{*}{$\begin{array}{l}\text { Sig. } \\
\\
.981\end{array}$} \\
\hline & & \multirow{2}{*}{$\begin{array}{l}\text { B } \\
.014\end{array}$} & \multirow{2}{*}{$\begin{array}{r}\text { Std. Error } \\
.571\end{array}$} & & & \\
\hline 1 & (Constant) & & & & & \\
\hline & Type of product & .026 & .140 & .023 & .185 & .855 \\
\hline & Positioning of product & -.130 & .086 & -.111 & -1.507 & .143 \\
\hline & Price of product & .215 & .080 & .215 & 2.688 & .012 \\
\hline & Quality of product & -.076 & .123 & -.070 & -.621 & .540 \\
\hline & Value of product & .527 & .119 & .528 & 4.433 & .000 \\
\hline & Attractiveness of product & .548 & .140 & .525 & 3.912 & .001 \\
\hline & Worthiness of product & -.136 & .137 & -.123 & -.987 & .332 \\
\hline
\end{tabular}

Source(s): Data Adapted from Khwanrat Chinda, 2016.

For Stimulus 2 the perception mean score for the smooth-emboss texture suggests that the targets perceive the emboss texture as the most for purchasing, and the multiple regression model with all seven predictors produced $\mathrm{R}^{2}=.962$ at sig. $=.000$. As Table 2 shows, the perceptions for positioning, and Attractiveness of product have significant positive regression weight, indicating that targets with higher perception scores will likely purchase the product, after controlling for the other variables in the model. Perceptions of type, price, quality, value, and Worthiness of product did not contribute to the multiple regression model.

Table 3. Results from the Regression Analysis of Stimulus 2 smooth texture and emboss texture

\begin{tabular}{|c|c|c|c|c|c|c|}
\hline \multicolumn{2}{|c|}{ Model } & \multicolumn{2}{|c|}{$\begin{array}{l}\text { Unstandardized } \\
\text { Coefficients }\end{array}$} & \multirow{2}{*}{$\begin{array}{c}\begin{array}{c}\text { Standardized } \\
\text { Coefficients }\end{array} \\
\text { Beta }\end{array}$} & \multirow[t]{2}{*}{$\mathbf{t}$} & \multirow[t]{2}{*}{ Sig. } \\
\hline & & B & Std. Error & & & \\
\hline \multirow[t]{8}{*}{1} & (Constant) & .197 & .192 & & 1.027 & .311 \\
\hline & Type of product & .063 & .076 & .055 & .829 & .412 \\
\hline & Positioning of product & -.124 & .047 & -.118 & -2.658 & .011 \\
\hline & Price of product & .078 & .054 & .069 & 1.440 & .158 \\
\hline & Quality of product & .033 & .044 & .032 & .744 & .461 \\
\hline & Value of product & .028 & .053 & .028 & .520 & .606 \\
\hline & Attractiveness of product & .811 & .055 & .869 & 14.655 & .000 \\
\hline & Worthiness of product & .076 & .061 & .070 & 1.236 & .224 \\
\hline
\end{tabular}

Source(s): Data Adapted from Khwanrat Chinda, 2016.

\section{DISCUSSION AND CONCLUSION}

The results suggest that even art and non art sensibility consumers have the same perceptions of the tested stimuli, however, there are still significant differences between the scores for perceived some factors of perception as type , attractive , and worthiness for both groups, by 0.5 point. Moreover, multiple 
regression analyses found that there is a high relation in the multiple regression model with some predictors. All perceptions have significant positive regression weight, indicating that consumers with higher perception scores are likely to purchase product.

In addition, the study found relation between elements of design and perception to convey the product value and trust to persuade the purchasers leading to the purchasing decision towards both of affective and cognitive perception that applied to use this elements on packaging design as follow: use medium color, emboss or cutting or glossy texture, high shape, wide typography, and combination mark logo.

\section{REFERENCES}

Ampuero, Olga, and Natalia Vila. 2006. "Consumer Perceptions of Product Packaging." Journalof Consumer Marketing 23 (2): 100-12.

Barbara \& Robert Sommer. 1997. A practical guide to behavioral research tools and techniques. Fourth edition. New york: Oxford university press.

Charles Wallschlaeger and Cynthia Busic-Snyder. 1992 Basic visual concepts and principles for artists, architects, and designers. United states of America: McGraw Hill companies.
David O’Hare. 1976 “Individual differences in perceived similarity and preference for visual art: A multidimensional scaling analysis." Journal of Perception \& Psychophysics 20 (6): 445-452

Hayden Noel. 2009. Consumer behavior. Lausanne 6. AVA Publishing SA.

Herbert M.Meyers and Murray J. Lubliner. 1998 Marketer's guide to successful package design. Illinois: NTC Business books.

Leon G.Schiffman and Leslie Lazar Kanuk. 2000 Consumer Behavior. Second edition. New Jersey: Prentice-hall, INC.

Linda Grote and David Wang.1954. Architectural research methods. New York:Print in the United tates of America. 23/2 (2006) 100-112 q Emerald Group Publishing Limited [ISSN 0736-3761][DOI 10.1108/07363760610655032]

Pires Gon calves, Ricardo,2008 http://mpra.ub.unimuenchen.de/11142/ Consumer Behavior: Product Characteristics and Quality Perception 